\title{
Prescribed psychiatric interventions for children presented to a university psychiatric clinic in Egypt: a descriptive cross-sectional study
}

\author{
Ahmed Sami Ghaly*, Salwa Mohamed Salah Tobar, Mohamed Adel El-Hadidy and Mahmoud Elwasify
}

\begin{abstract}
Background: The number of children diagnosed with psychiatric disorders has significantly increased over the past two decades. This study examined the pattern of psychiatric interventions prescribed for a sample of children with mental health problems in Egypt. A descriptive cross-sectional study was conducted to examine the pattern of psychotropic drug prescribing and intervention (medication, doses, duration, side effects, and improvement) in children aged 2-12 years old in primary and secondary health settings, presented to Mansoura University Hospitals in Egypt over 1 year. The identified patterns were compared with the Maudsley guidelines to detect any significant deviations.

Results: Among the 272 cases presented to the clinic, attention-deficit hyperactivity disorder (ADHD) and disruptive behavior disorders were the most prevalent diagnoses (85.3\%) followed by intellectual disability (7.8\%) and autism spectrum disorder (ASD; 5.1\%). Antipsychotic drugs and ADHD medications (atomoxetine and methylphenidate) represented the most commonly prescribed medications ( $56.6 \%$ and $44.5 \%$ respectively), whereas behavioral therapy was among the least chosen (8.5\%) treatment options. About 1/3 of the sample received multiple psychotropic medications. The prescribed intervention strategies did not match the Maudsley's guidelines in $76 \%$ of the cases with the absence of psychotherapeutic interventions being the most frequently observed factor (95.7\%). Although still inadequate, psychiatrists' intervention strategies were more likely to follow the Maudsley's guidelines (38.3\%), whereas pediatricians and neurologists were almost oblivious to them.
\end{abstract}

Conclusions: Current pattern of psychiatric interventions prescribed for a sample of children with mental health problems in Egypt are not in accordance with standard guidelines, such as "Maudsley's," rendering it imperative to provide relevant educational programs for health care providers.

Keywords: Intervention pattern, Psychotropic drug prescriptions, Mental health, Children

\section{Background}

The number of children diagnosed with psychiatric disorders as well as the use of psychotropic drugs in children has increased significantly in the past two decades [1]. A population-based analysis of Texas Medicaid system prescriptions claims denoted that between 1998 and 2001 , the prevalence of antipsychotic prescriptions in

* Correspondence: Ahmed.yomo@gmail.com

Faculty of Medicine, Mansoura University, Shobrababel, Elmahalla elkobra, El-Gharbia governate, Egypt

Springer Open children aged from 3 to 14 years increased from 6.3 to $15.5 \%$ [2]. Zuvekas and Vitiello reported a slow but steady increase in the use of stimulant medications for ADHD treatment in the USA during the period 19962008, primarily due to greater use in adolescents [3]. However, significant deficits have been frequently identified within the relevant literature, such as the off-label prescription of psychotropic medications for children [4], and the long-term safety and efficacy of their use, especially when these medications are prescribed for very

(c) The Author(s). 2020 Open Access This article is licensed under a Creative Commons Attribution 4.0 International License, which permits use, sharing, adaptation, distribution and reproduction in any medium or format, as long as you give appropriate credit to the original author(s) and the source, provide a link to the Creative Commons licence, and indicate if changes were made. The images or other third party material in this article are included in the article's Creative Commons licence, unless indicated otherwise in a credit line to the material. If material is not included in the article's Creative Commons licence and your intended use is not permitted by statutory regulation or exceeds the permitted use, you will need to obtain permission directly from the copyright holder. To view a copy of this licence, visit http://creativecommons.org/licenses/by/4.0/. 
young children [5]. Often, their use in children is based mainly on extrapolation of information from adult studies [6]. Consequently, there is an urgent need to assess the risks, benefits, and costs of medication use and understand the local and national policies that affect their use [7]. To the best of our knowledge, the present study is the first study in Egypt that reviews and summarizes the pattern of psychiatric interventions prescribed for children, as well as its discrepancies from evidencebased practices, such as Maudsley guidelines. The reason we chose "The Maudsley guidelines" over the other international ones was that we considered them as more practical and useful in commonly encountered clinical situations and it has a heavy reliance on NICE guidelines following the same broad aim. Moreover, it is a referenced prescribing guideline which is specialized in the field of mental illness and psychotropic drugs. That is why we decided to rely on it rather than NICE guidelines. The presented results could help us in improving current practices in primary and secondary children's mental health settings, providing the highest possible care for our patients through building upon advanced available international guidelines.

\section{Aim of the study}

Assess the degree of concordance between psychotropic medications prescribed for children referred to child psychiatry clinic, Mansoura University Hospitals and the Maudsley guidelines.

\section{Methods}

This was a descriptive cross-sectional study that was carried out in the child psychiatry outpatient clinic of Mansoura University Hospitals (MUH) between 1 May 2015, and 31 May 2016. The child and adolescent mental health services of MUH provide for 40-60 cases per month, accepting all cases presented, even walk-in new cases.

\section{Subjects}

Our sample included all children aged 2 to 12 years old presented to CAMHS University clinics for the first time, and having been prescribed previously with a psychotropic drug (antipsychotics, antidepressants, anticonvulsants, benzodiazepines, stimulants, and atomoxetine) from any secondary clinic (psychiatry, neurology, pediatric) or primary health center. The reason for excluding unprescribed patients was the fact that the absence of a centralized registry in Egypt prevented us from access in records that would have given us an insight for the strategy followed in these cases and thus examining if their management went along with the standard guidelines.

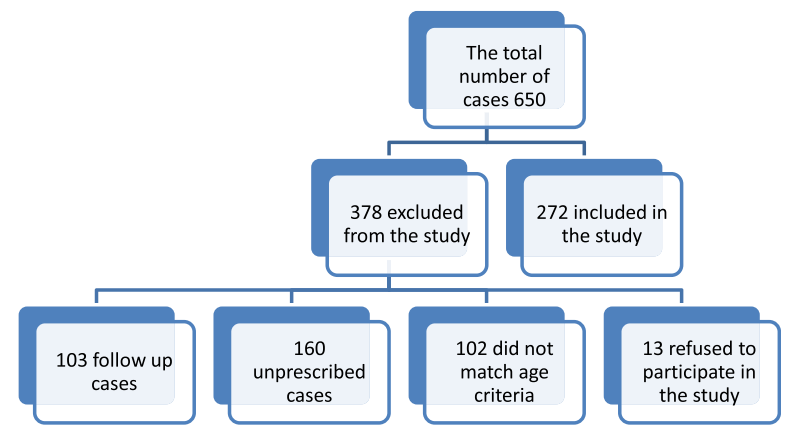

\section{Ethics}

In accordance with the Declaration of Helsinki, the study was carried out after the approval of the Faculty of Medicine Mansoura University ethical committee. Participation was on a voluntary basis, and written informed consent was obtained from parents, after educating them about the aim and methods of the study. Data sheets were stored in a locked cabinet in the work place and electronically stored in a password-protected workplace $\mathrm{PC}$, using an identification number and without any identifying information.

\section{Procedures and data collection}

Patients meeting the inclusion criteria and their guardians were interviewed using the Arabic version of MINI KID [8] to corroborate their psychiatric diagnoses. A consensus diagnosis was finally given after data were independently assessed by two consultant child psychiatrists. The study population psychiatric interventions (psychotherapeutic interventions and pattern of psychotropic drug prescriptions) were subsequently reviewed. For the psychological interventions, we assumed that one was performed only if the parents reported the attendance of a number of sessions on regular basis and/ or homework was given to both the parents and the child. We chose this approach, as this would be closer to the concept of psychotherapy as it is used in the guidelines. For the psychotropic drug prescriptions, we collected data on the medication prescribed, duration, side effects, and effectiveness. Finally, we compared these interventions against the Maudsley guidelines, 12th edition [9]. Agreement was characterized as total, partial (lack of psychotherapeutic intervention and/or dosage differences) or poor (the drug is not indicated for the condition, use of polypharmacy, or the drug is not appropriate for age).

\section{Statistical analysis}

Original sample size calculation required 139 people or more to have a confidence level of $95 \%$ that the real value is within $\pm 5 \%$ (margin of error) of the measured 
value. With type I error (alpha) at the 0.05 level, the study would have been powered at $80 \%$.

This means, in our study with a sample size of 272 people, there is a $95 \%$ chance that the real value is within $\pm 3.57 \%$ of the measured value.

Data were entered and statistically analyzed using SPSS version 23 (SPSS Inc., Chicago, IL, USA). The normality of data was first tested with one-sample Kolmogorov-Smirnov test.

Qualitative data were described using number and percent. Association between categorical variables was tested using chi-square tests. Continuous variables were presented as median (minimum-maximum) for nonparametric data. Statistical differences were considered significant at a $P$ value less than or equal to 0.05 .

\section{Results}

From the total of 650 cases presented in our clinic during the surveyed period, 547 were new cases. From these, 102 were above the age criterion (2-12 year), 13 refused to participate, and 160 were unprescribed cases, and thus the sample consisted of 272 subjects.

As shown in Table 1, data from 272 cases were analyzed. Participants had a median age of 7 years with males' predominance (75.7\%). ADHD and disruptive behavior disorders (ODD and conduct disorder as the predominant presentation) were the most common diagnoses ( $85.3 \%$ of the sample) followed by intellectual disability and ASD (7.8 and 5.1\% respectively). From the total sample presented, 72 patients have already shown good improvement on their difficulties and from the

Table 1 Sample characteristics

\begin{tabular}{ll}
\hline Demographic characteristics & $\boldsymbol{n}=\mathbf{2 7}, \mathbf{n u m b e r}(\%)$ \\
\hline Age & Median =7 years, range 2-12 years \\
2-4 years & $12(4.4 \%)$ \\
4-6 years & $34(12.5 \%)$ \\
6-12 years & $226(83.1 \%)$ \\
Gender & \\
Male & $206(75.5 \%)$ \\
Female & $66(24.3 \%)$ \\
Psychiatric diagnoses & \\
ADHD & $173(63.6 \%)$ \\
Autism spectrum disorder & $14(5.1 \%)$ \\
Conduct disorder & $25(9.2 \%)$ \\
Intellectual disability & $21(7.8 \%)$ \\
ODD & $34(12.5 \%)$ \\
Separation anxiety disorder & $3(1.2 \%)$ \\
Social phobia & $1(0.4 \%)$ \\
Depression & $1(0.4 \%)$ \\
\hline
\end{tabular}

rest, 155 were seen for 6 months or less. Thus, 227 patients $(83.5 \%)$ could not be characterized as resistant or complicated cases.

Antipsychotics and ADHD medications (atomoxetine and methylphenidate) represented the most commonly prescribed medications (56.6\% and $44.5 \%$ respectively). Behavioral therapy, on the other hand, was among the least chosen $(8.5 \%)$ as a treatment option.

About one-third of the sample received multiple psychotropic medications (Table 2).

Prescriptions for ADHD comprised either methylphenidate or atomoxetine alone for less than half of the patients, combined prescription for about one-third, and antipsychotics for about $20 \%$ of the participants. More than half of cases with ASD, CD, ID, and ODD were prescribed antipsychotics, with the rest receiving anticonvulsants, methylphenidate or atomoxetine, or combined medications prescriptions (Table 3). Five cases had no clear diagnosis from the previous centers and were treated with multivitamins and omega-3.

In a staggering $76 \%$ of the cases, the prescribed intervention strategy was not in accordance with the Maudsley guidelines (42\% poor agreement and $34 \%$ partial agreement), with the absence of psychotherapeutic intervention being the most frequently observed factor (96.1\%), followed by use of a medication not appropriate for age (47.8\%) or not indicated for the disorder (46.3\%), higher prescribed doses (37.2\%), and polypharmacy (35.2\%).

Psychiatrists' intervention strategies exhibited the highest concordance rate (however still inadequate) with the Maudsley guidelines (38.3\%), with the pediatricians and neurologists being almost oblivious to them (Table 4).

Table 5 showed that about two-thirds of initial diagnosis of the studied group was agreed with MINIKID. The table also showed that the psychiatrists have the highest diagnostic accuracy $85.6 \%$ than non-psychiatrists, pediatricians $47.7 \%$, and neurologists $35 \%$.

Table 6 showed that the percentage of agreement for cases provisionally diagnosed with ADHD versus MINI

Table 2 Distribution of psychotropic drug prescription and interventions* within the studied group

\begin{tabular}{lll}
\hline Drug categories & $\begin{array}{l}\text { No. (\%), } \\
\boldsymbol{n = ~ 2 7 2}\end{array}$ & Mono or polypharmacy (\%) \\
\hline Antipsychotics drugs & $154(56.6 \%)$ & Monotherapy, $187(67.3)$ \\
Stimulants & $27(9.9 \%)$ & \\
Atomoxetine & $94(34.6 \%)$ & Polypharmacy, $89(32.7)$ \\
Anticonvulsants & $42(15.4 \%)$ & \\
Antidepressants & $15(5.5 \%)$ & $\begin{array}{l}\text { No. of medications median } \\
\text { (min.-max.), 2 (2-5) }\end{array}$ \\
$\begin{array}{l}\text { Psychotherapeutic } \\
\text { interventions }\end{array}$ & $23(8.5 \%)$ & \\
\hline${ }^{*}$ Categories not mutually exclusive &
\end{tabular}


Table 3 Distribution of psychotropic drug prescription per each original diagnosis*

\begin{tabular}{|c|c|c|c|c|c|}
\hline \multirow{2}{*}{$\begin{array}{l}\text { Drugs } \\
\text { prescribed }\end{array}$} & \multicolumn{5}{|c|}{ Diagnoses $(n=267)$} \\
\hline & $\mathrm{ADHD}(n=173)$ & ASD $(n=14)$ & Conduct disorder $(n=25)$ & Intellectual disability $(n=21)$ & ODD $(n=34)$ \\
\hline Stimulants & $22(12.7 \%)$ & & & & $5(14.7 \%)$ \\
\hline Atomoxetine & $52(30.1 \%)$ & & $3(12.0 \%)$ & & $3(8.8 \%)$ \\
\hline Antipsychotic & $33(19.1 \%)$ & $10(71.4 \%)$ & $16(64.0 \%)$ & $11(52.4 \%)$ & $18(52.9 \%)$ \\
\hline Anticonvulsant & $11(6.4 \%)$ & $4(28.6 \%)$ & & $1(4.8 \%)$ & $5(14.7 \%)$ \\
\hline Polypharmacy & 55 (31.8\%) & & $6(24.0 \%)$ & $9(42.9 \%)$ & $3(8.8 \%)$ \\
\hline
\end{tabular}

*5 cases with no prior diagnosis and treated with multivitamins and omega-3

KID was about $80 \%$, while autistic disorder and MR was agreed with a percentage of $91 \%$, regarding CD was totally agreed. Only half of the cases of ODD were agreed with MINIKID. About of cases diagnosed with epilepsy met the criteria of ADHD and the rest met the criteria of $\mathrm{CD}$ and MR.

\section{Discussion}

In the present study, boys represented $75.7 \%$ of the study population. This is mainly due to the diagnostic preponderance of ADHD, disruptive behaviors, and developmental disorders in a sample of $83.1 \%$ primary school aged children given that these disorders are more common among boys $[10,11]$, and that boys tend to be referred more often [12]. Almost one-third of the sample received polypharmacy, an alarming phenomenon that is present in both developed [13], and developing countries [14]. Comer et al. analyzed data of 3466 child and adolescent visits to office-based physicians in the USA and reported an increase in the percentage of polypharmacy from 14.3 (1996-1999) to $32.2 \%$ (2004-2007) [15].

The most common pharmacological combination in our sample was antipsychotics plus ADHD medications, which also seems to be the case in other settings [15, 16]. Although the rationale behind the clinical decisions concerning psychotropic co-prescription was not routinely documented, the main reasons for polypharmacy could be the state of emergency represented by disorders accompanied with aggressiveness and externalizing behavioral symptoms, as well as a tendency toward symptom-based management [17]. This practice may not necessarily be improper as it is useful in some clinical situations, such as the treatment of adverse effect of another agent, co-existing conditions (e.g., seizure and psychosis), and immediate relief of symptoms before having symptomatic improvements resulting from the main medication [18].

The agreement between the observed intervention pattern in the sample and the Maudsley guidelines was extremely low, even among the psychiatrists. Bazzano and colleagues examined data from the 2004 National Ambulatory Medical Care Surveys and reported that $62 \%$ of pediatric outpatient visits involved off-label prescriptions and deviations from prescribing guidelines across all medication categories, with the off-label prescribing being more frequent for younger children [19].

However, the main deviation of the observed intervention pattern in this sample and the Maudsley guidelines was the absence of psychotherapeutic intervention, although these interventions are considered a first-line treatment for conditions such as mild cases of ADHD, social phobia, mild to moderate depression, and generalized anxiety disorder [20]. This phenomenon could be attributed to several factors such as the high costs of psychotherapy in private settings and the lack of such resources in many communities, especially in developing countries, that renders pharmacotherapy a more readily available option for many [20]. More specific reasons might be the paucity of psychotherapeutic training in Egypt, which lacks a clinical board of psychotherapy, as well as other cultural reasons pertaining to avoidance of intense and long involvement with mental health specialists. Finally, specific characteristic of the study design and sample could also account for this phenomenon, namely, the exclusion of unprescribed children who might be receiving psychotherapy, the number of cases

Table 4 Intervention strategies agreement with Maudsley guidelines per prescriber

\begin{tabular}{llll}
\hline Prescriber & \multicolumn{2}{l}{ Agreement of prescriptions with Maudsley guidelines } & \\
\cline { 2 - 4 } & Poor agreement & Partial agreement & Agreement \\
& No. (\%) & No. $(\%)$ & No. (\%) \\
\hline Pediatrician $(n=65)$ & $42(60.0 \%)$ & $23(33.8 \%)$ & $4(6.1 \%)$ \\
Neurologist $(n=40)$ & $31(77.5 \%)$ & $8(20.0 \%)$ & $1(2.5 \%)$ \\
Psychiatrist $(n=167)$ & $41(24.6 \%)$ & $62(37.1 \%)$ & $64(38.3 \%)$
\end{tabular}


Table 5 Agreement of provisional diagnosis with MINIKID for each prescriber specialty

\begin{tabular}{clll}
\hline & \multicolumn{2}{l}{$\begin{array}{l}\text { Agreement of provisional } \\
\text { diagnosis with MINIKID }\end{array}$} & \\
\cline { 2 - 3 } & $\begin{array}{l}\text { Disagreed } \\
\text { No. (\%) }\end{array}$ & $\begin{array}{l}\text { Agreed } \\
\text { No. (\%) }\end{array}$ & \\
\hline Total $(n=272)$ & $84(30.9)$ & $188(69.1)$ & \\
Prescriber Pediatrician $(n=65)$ & 34 & 31 & $\leq 0.001$ \\
& $(52.3 \%)$ & $(47.7 \%)$ & \\
Neurologist $(n=40)$ & 26 & 14 & \\
& $(65.0 \%)$ & $(35.0 \%)$ \\
Psychiatrist $(n=167)$ & 24 & 143 \\
& $(14.4 \%)$ & $(85.6 \%)$ \\
\hline
\end{tabular}

Chi-square test

that was treated by either pediatricians or neurologists who lack knowledge and experience in psychotherapy in comparisons with psychiatrists, and the distribution of diagnoses of the sample subjects (i.e., few cases with anxiety and depression, while the fact that were referred for their neurodevelopmental symptoms to a tertiary center probably signifies that their cases were more severe and complicated).

Off-label use of medications and higher-than-indicated prescribed doses were also often causes of discrepancy from the guidelines. This phenomenon is generally more common among pediatric population [21], with

Table 6 Agreement of provisional diagnosis with MINIKID for each diagnosis

\begin{tabular}{lll}
\hline Provisional diagnosis & Diagnosis by MINIKID & No. (\%) \\
\hline ADHD $(n=162)$ & ADHD & $134(82.7)$ \\
& ODD & $12(7.4)$ \\
& Conduct disorder & $7(4.3)$ \\
& Mental retardation & $6(3.7)$ \\
& Separation anxiety disorder & $2(1.2)$ \\
& Autistic disorder & $1(0.6)$ \\
ODD $(n=43)$ & ODD & $22(51.2)$ \\
& ADHD & $18(41.9)$ \\
& Conduct disorder & $2(4.7)$ \\
Epilepsy ( $n=21)$ & Mental retardation & $1(2.3)$ \\
& ADHD & $16(76.2)$ \\
& Mental retardation & $3(14.3)$ \\
Conduct disorder $(n=14)$ & Conduct disorder & $2(9.5)$ \\
Pervasive developmental \\
disorder (autistic disorder) \\
$(n=12)$
\end{tabular}

antipsychotics, for instance, being prescribed outside their approved indications in $54.2 \%$ of their use, both in specialized and non-specialized childcare settings [22]. This study reveals significant weaknesses in the management of children with mental health problem in primary care settings in Egypt. Although some common setbacks pertaining in caring for this population worldwide, our study revealed a big gap in the primary or combined use of psychotherapeutic interventions and the safe and appropriate use of medications according to the international literature. These warrant to be readily dealt by health providers, both through expanding the relevant training and informing all primary health care workers about evidence-based practices.

\section{Limitations}

The lack of available detailed file data and the use mainly of the history provided by the parents make our results more prone to recall bias. For the same reason, we had to exclude unprescribed patients which, on one hand prevented us to assess their management and on the other may have compromised the generalizability of our conclusions, given the fact that the cases we did assess could have been the more severe ones, thus needing a medication.

Furthermore, the cases presented to our tertiary center after a prior consultation elsewhere, could have been a non-representative sample consisting of the more complicated resistant cases, which in its turn could explain the non-adherence to classical guidelines. The late seems not to be the case, for the following reasons: (a) the referral system in Egypt is not following the strict protocols seen in developed countries and a case to be seen does not need to have a referral from primary or secondary health care providers. Actually, cases can choose to be seen in a tertiary clinic as a first visit; (b) $83.5 \%$ of our sample were definitely not seen as resistant or complicated cases. Another limitation is that our data could be relatively old as the study was conducted from May 2015-May 2016, which is more than 5 years ago, as data could be somewhat changed now.

\section{Conclusions}

Current pattern of psychiatric interventions prescribed for a sample of children with mental health problems in Egypt are not in accordance with standard guidelines, such as Maudsley guidelines, rendering it imperative to provide relevant educational programs for health care providers, with special focus at the non-psychiatrists.

\section{Abbreviations}

ADHD: Attention deficit hyperactivity disorder; ASD: Autism spectrum disorder; CAMHS: Child and Adolescent Mental Health Services; CD: Conduct disorder; ID: Intellectual disability; NICE: National Institute for Health Care and 
Excellence; ODD: Oppositional defiant disorder; USA: United States of America

\section{Acknowledgements \\ No acknowledgment to be included}

\section{Authors' contributions}

A.G.: Major contribution in writing the manuscript, conducting practical part of the study, ensuring that all listed authors have approved the manuscript before submission and verifying that all data, figures, materials provided, comply with the standards of both field and journal. M.W.: Contributed in writing the manuscript, idea of the research, and design of the work. Also provided a consensus diagnosis after data were independently collected. M.H.: Contributed in designing research methodology. Acquisition, analysis, and interpretation of data. S.T.: Reviewing the manuscript and provided a consensus diagnosis after data were independently collected. All authors have read and approved the manuscript.

\section{Funding}

No funding was obtained for the presented research.

\section{Availability of data and materials}

Data is available upon request.

\section{Ethics approval and consent to participate}

In accordance with the Declaration of Helsinki, the study was carried out after the approval of the Faculty of Medicine Mansoura University ethical Committee (no reference number available). Participation was on a voluntary basis, and written informed consent was obtained from parents, after educating them about the aim and methods of the study. Data sheets were stored in a locked cabinet in the work place and electronically stored in a passwordprotected workplace PC, using an identification number and without any identifying information.

\section{Consent for publication}

As a corresponding author, I confirm that the manuscript has been read and approved for submission by all the named authors.

\section{Competing interests}

There is no conflict of interest associated with this publication.

Received: 8 June 2020 Accepted: 10 September 2020

Published online: 20 November 2020

\section{References}

1. Frank RG, Conti RM, Goldman HH (2005) Mental health policy and psychotropic drugs. The Milbank Quarterly. 83(2):271-298

2. Patel NC (2004) Antipsychotic use in children and adolescents from 1996 to 2001: epidemiology, prescribing practices, and relationships with service utilization

3. Zuvekas SH, Vitiello B (2012) Stimulant medication use in children: a 12-year perspective. Am J Psychiatry. 169(2):160-166

4. Nardi DA, Barrett S (2005) Potential effects of antidepressant agents on the growth and development of children and adolescents. Journal of psychosocial nursing and mental health services. 43(1):22-35

5. Efron D, Hiscock H, Sewell JR et al (2003) Prescribing of psychotropic medications for children by Australian pediatricians and child psychiatrists. Pediatrics. 111(2):372-375

6. Rey JM, Omigbodun $\mathrm{OO}$ (2015) International dissemination of evidencebased practice, open access and the IACAPAP textbook of child and adolescent mental health. Child Adolesc Psychiatry Ment Health. 9(1):51

7. Mandell DS, Morales KH, Marcus SC et al (2008) Psychotropic medication use among Medicaid-enrolled children with autism spectrum disorders. Pediatrics. 121(3):e441-e4e8

8. Ghanem M, Ibrahim M, Elbehery A, et al: The translation group of the Arabic version of the Mini International Neuropsychiatric Interview for Children (MINI-Kid) by Sheehan DV et al, 1998. Department of Neuropsychiatry Ain Shams University. 2000.

9. Taylor D, Paton C, Kerwin R: The Maudsley prescribing guidelines in psychiatry: CRC Press; 2015
10. Pastor PN, Reuben CA: Diagnosed attention deficit hyperactivity disorder and learning disability: United States, 2004-2006. Vital and Health Statistics Series 10, Data from the National Health Survey. 2008(237):1-14.

11. Bauermeister JJ, Shrout PE, Chávez L et al (2007) ADHD and gender: are risks and sequela of ADHD the same for boys and girls? J Child Psychol Psychiatry. 48(8):831-839

12. Derks EM, Hudziak JJ, Boomsma DI (2007) Why more boys than girls with $\mathrm{ADHD}$ receive treatment: a study of Dutch twins. Twin Res Hum Genet. 10(5):765-770

13. Kukreja S, Kalra G, Shah N et al (2013) Polypharmacy in psychiatry: a review. Mens Sana Monographs 11(1):82

14. Russell PS, George C, Mammen P (2006) Predictive factors for polypharmacyamong child and adolescent psychiatry inpatients. Clin Pract Epidemiol Ment Health. 2(1):25

15. Comer JS, Olfson M, Mojtabai R: National trends in child and adolescent psychotropic polypharmacy in office-based practice, 1996-2007. J Am Acad Child Adolesc Psychiatry. 2010;49(10):1001-10.

16. Mojtabai R, Olfson M (2010) National trends in psychotropic medication polypharmacy in office-based psychiatry. Archives of General Psychiatry. 67(1):26-36

17. Saldaña SN, Keeshin BR, Wehry AM et al (2014) Antipsychotic polypharmacy in children and adolescents at discharge from psychiatric hospitalization. Pharmacotherapy: The Journal of Human Pharmacology and Drug Therapy. 34(8):836-844

18. Olashore A, Ayugi J, Opondo P (2017) Prescribing pattern of psychotropic medications in child psychiatric practice in a mental referral hospital in Botswana. Pan Afr Med J. 26

19. Bazzano AT, Mangione-Smith R, Schonlau M et al (2009) Off-label prescribing to children in the United States outpatient setting. Academic pediatrics. 9(2):81-88

20. James AC, James G, Cowdrey FA et al (2015) Cognitive behavioral therapy for anxiety disorders in children and adolescents. The Cochrane Library.

21. Jensen PS, Buitelaar J, Pandina GJ et al (2007) Management of psychiatric disorders in children and adolescents with atypical antipsychotics. Eur Child Adolesc Psychiatry. 16(2):104-120

22. Woods G, Shannon C, Davidson G et al (2016) Psychotropic prescribing patterns among adolescents in Northern Ireland presenting with psychotic symptoms during a 5-year period. Irish J Psychol Med. 33(1):13-20

\section{Publisher's Note}

Springer Nature remains neutral with regard to jurisdictional claims in published maps and institutional affiliations.

\section{Submit your manuscript to a SpringerOpen ${ }^{\circ}$ journal and benefit from:}

- Convenient online submission

- Rigorous peer review

- Open access: articles freely available online

High visibility within the field

- Retaining the copyright to your article

Submit your next manuscript at $>$ springeropen.com 